\title{
Neurodevelopmental Outcomes of Preterm Small for Gestational Age and Appropriate for Gestational Age Babies at One Year of Age
}

\author{
Rino Rakesh Kesary Rani1 ${ }^{1}$ Babu Francis Chirayath Antony², Aslam Pala Kuzhiyil ${ }^{3}$ \\ 1, 2, 3 Department of Paediatrics, Government Medical College, Kozhikode, Kerala, India.
}

\section{ABSTRACT}

\section{BACKGROUND}

It is well known that prematurity causes several complications during the neonatal period and affects the neurodevelopment. But comparison of small for gestational age (SGA) and appropriate for gestational age (AGA) on prematurity-associated outcome has been disputed due to inconsistent results in the literature. The objective of this study was to compare the neurodevelopmental outcome at 1 year between preterm SGA and AGA infants. We also aimed at investigating short-term neonatal outcome variables in SGA-infants compared with AGA-infants.

\section{METHODS}

A prospective study was done among 213 infants born without congenital anomalies between 30 weeks and 34 weeks of gestation and admitted to the neonatal intensive care unit (NICU), Govt Medical College, Kozhikode, during a period of six months. Modified Fenton chart was used to classify neonates as SGA $\left(<10^{\text {th }}\right.$ percentile for GA) or AGA $\left(10^{\text {th }}-90^{\text {th }}\right.$ percentile for GA). Infants were grouped into SGA $(n=80)$ and AGA ( $\mathrm{n}=133$ ). Neonatal complications like RDS (Respiratory Distress Syndrome), hypoglycaemia, polycythaemia, hypocalcaemia, thrombocytopenia, neonatal hyperbilirubinaemia, sepsis, DIC (Disseminated Intravascular Coagulation), Necrotizing Entero-Colitis (NEC), PDA (Patent Ductus Arteriosus), Intra Ventricular Haemorrhage (IVH), apnoea, pulmonary haemorrhage and mortality were compared. Neurodevelopmental outcome at 1 year was assessed using Bayley Scales of Infant and Toddler Development $3^{\text {rd }}$ edition. Analysis was done using SPSS statistical program.

\section{RESULTS}

Proportion of preterm SGA infants with hypoglycaemia (AGA: $20.3 \%$, SGA: $55 \%$ p = $<.001$ ), hypocalcaemia (AGA: $3.8 \%$, SGA: $16.2 \% \mathrm{p}=.002$ ) and NEC (AGA: $9.8 \%$, SGA: $20 \% \mathrm{p}=.035$ ) were significantly higher than AGA infants. Need for surfactant therapy in RDS is more for preterm AGA infants than SGA infants (AGA: $16.5 \%$, SGA: $13.8 \%$ $\mathrm{p}=0.841$ ). Development of thrombocytopenia, neonatal hyperbilirubinaemia, sepsis, DIC, apnoea and pulmonary haemorrhage is observed more with SGA infants than AGA infants but lacks statistical significance. $6 \%$ of AGA infants had PDA while for SGA it was $2.5 \%$. No significant difference was noticed in the occurrence of polycythaemia and IVH among the groups. Mortality was also comparable (AGA: 11.3 \%, SGA: $10 \%$ ). SGA infants perform significantly lower when compared to AGA infants in cognitive, language and motor outcomes at 1 year. Severe developmental delay was also observed significantly more commonly with SGA infants.

\section{CONCLUSIONS}

Being born small for gestational age is additionally associated with neurodevelopmental delay for preterm babies at the age of 1 year. NEC and metabolic complications like hypoglycaemia and hypocalcaemia are significantly increased in preterm SGA babies when compared to preterm AGA babies. Several other neonatal complications except for severe RDS are also more common among preterm SGA infants although they lack statistical significance.

\section{KEY WORDS}

Infant, Small for Gestational Age, Preterm, Neurodevelopment
Corresponding Author: Babu Francis Chirayath Antony, Department of Paediatrics, Government Medical College, Manjeri-676121, Kerala, India. E-mail: babufrancisca@gmail.com

DOI: $10.14260 / j e m d s / 2020 / 709$

How to Cite This Article:

Rani RRK Antony BCC, PalaKuzhiyil A. Neurodevelopmental outcomes of preterm small for gestational age and appropriate for gestational age babies at one year of age. J Evolution Med Dent Sci 2020;9(43): 3231-3236 DOI:

10.14260/jemds/2020/709

Submission 20-07-2020,

Peer Review 16-09-2020,

Acceptance 23-09-2020,

Published 26-10-2020.

Copyright (c) 2020 Rino Rakesh Kesary Rani et al. This is an open access article distributed under Creative Commons Attribution License [Attribution 4.0 International (CC BY 4.0)] 


\section{BACKGROUND}

There is six times higher risk in underdeveloped / developing countries for a baby to be born as SGA when compared to that in developed countries. Amongst the Asian countries, India stands second in the incidence for Low Birth Weight (LBW) and Intra-Uterine Growth Restriction (IUGR), IUGR-LBW. ${ }^{1}$

Although premature SGA infants have higher mortality than AGA infants, the differences in respiratory and nonrespiratory morbidity are controversial. ${ }^{2}$ Studies done by Gluck L et al, Procianoy RS et al and Yamaguchi K et al showed that SGA infants have fewer respiratory complications in the neonatal period than AGA infants.3,4,5 But the outcome of studies conducted by Robertson CMT et al, Sung IK et al, Pena IC et al and Ruys Dudok van Hell et al were inconclusive.6-9 Within each gestational age group from 25 to 32 weeks, IUGR was associated with increased mortality, necrotizing enterocolitis, chronic lung disease, and retinopathy of prematurity. IUGR was shown to be a serious problem that is associated with increased morbidity and mortality among prematurely born neonates. Antenatal diagnosis of IUGR correlated well with neonatal diagnosis of SGA and was correlated with the same adverse outcomes. ${ }^{10}$

Studies by Punnet Sharma et al, Procianoy et al, Yoon J J et al, Warshaw J B et al showed that, the premature SGA infants were at a lower risk for RDS than premature AGA infants.2,4,11 However, other studies by Bardin C et al, Gortner et al, Pena et al and Simchen MJ had found no difference between the two groups ${ }^{8,12}$. But an increased incidence and severity of RDS in premature SGA infants was noted in the studies by Tyson JE et al and Thompson $\mathrm{P} J$ et al 13,14 . The postulation, that growth restricted fetuses have accelerated lung maturation resulting from intra uterine "stress" and thus lower incidence of RDS when compared to AGA infants, lacks evidence. In the study by Zaw W et al, a higher incidence of RDS among SGA infants was noted with use of the fetal growth standard but no difference was noted between SGA and AGA infants with use of the neonatal growth standard. The study done by Puneet Sharma et al revealed that while the incidence of RDS in SGA infants was lower as compared to AGA infants, the total number of ventilator days in both the groups is not different. 4

Studies done by Bardin et al, Thompson et al, Teberg et al and Chen et al found an increased incidence of sepsis and related mortality among SGA compared to AGA babies. ${ }^{12,14}$ In the study by Bardin et al, infection was suspected or confirmed more frequently in SGA infants, especially during the first week of life.

The study by Bardin et al showed that even though the incidence of necrotizing enterocolitis was not significantly different between the two groups, the SGA infants had more difficulties with enteral feedings. ${ }^{12}$

Study by Procianoy et al suggested that an SGA infant with the same risk factors for IVH as an AGA infant has a lower probability of developing clinical IVH. ${ }^{4}$

Developmental delay rather than survival is now recognized as the main problem in children born preterm and SGA $^{15}$ MRI studies in preterm children suggest that IUGR is associated with a decreased cortical grey matter volume in the neonatal brain. ${ }^{16}$ Moreover, structural brain alterations in IUGR newborns have been pointed out by a recent study on the hippocampal volume using 3D MRI.17 The hippocampus is known to be highly vulnerable to environmental factors as hypoxia and ischaemia during brain development. ${ }^{17}$ In addition, the number of proliferating neurons and the maturation of neurons in the brain were found to be reduced in animal studies as a result of IUGR. Possible mechanisms are decreased expression of neuronal growth factors like the Brain Derived Neurotrophic Factor (BDNF) and the glial neurotrophic factor S-100 beta. ${ }^{18}$ It is not evident, whether the effects on neuronal proliferation and maturation, and changes in MRI are transient or result in subtle brain dysfunction like minimal cognitive impairment. As mentioned above, in addition to neonatal complications and changes in brain maturation, the socioeconomic background and the mother's educational level seem to influence the development of preterm infants. ${ }^{19}$

Studies comparing the neurodevelopmental outcomes of preterm SGA and AGA babies showed inconsistent results in the literature. Studies in which the intellectual abilities of SGA infants were assessed by standardized IQ tests found a lower IQ in the SGA group. ${ }^{20,21}$ More specific analyses of the cognitive development showed difficulties in language and social skills. ${ }^{21-23}$ Several studies done by Sung et al, Mc Carton CM et al, Feldman R et al, Frauz A R et al, Guellec I et al and Morsing E et al had shown that among children whose birth weight was in the lowest decile for gestational age, tend to be at increased risk of cognitive limitations.7,24-28 On the contrary study by Kan $E$ et al found no association between fetal growth restriction and cognitive limitations.29 Studies by Guellec I et al and Morsing $\mathrm{E}$ et al have identified magnitude of the growth restriction and sex of the child as factors that influence growth restriction and development in children born at a low gestational age.27,28 According to the study by Iris G. Streimish et al, only severe growth restriction is associated with delayed development. They also concluded that the neurosensory limitations appeared to obscure increased risks of low Mental Development Index in girls with severe growth restriction, and low Psychomotor Development Index in boys with even less severe growth restriction. ${ }^{30}$

Apart from severe neurological impairment, $32-44 \%$ of all preterm children with birth weights $<1500 \mathrm{~g}$ showed mental developmental deficits when tested at the age of 5 years. ${ }^{31}$

\section{METHODS}

This is a prospective observational study conducted in the Neonatal Intensive Care Unit, Government Medical College, Kozhikode.

\section{Sample Size}

Study conducted by Streimish et al at 14 institutions in the United States ${ }^{28}$ showed that the neurodevelopmental delay for preterm SGA infants is $37 \%$ and that for preterm AGA infants is $18 \%$. Sample size determination for estimating difference between proportions

$$
n=\frac{(\mathrm{Z} \alpha+\mathrm{Z} \beta)^{2} \mathrm{pq} \times 2}{\mathrm{~d}^{2}}
$$

Considering a dropout of $10 \%$, minimum sample size is calculated as 190 preterm babies with 95 babies in each group. 


\section{Duration of the Study}

6 months for recruitment of subjects. Follow up at 1 year from the day of recruitment.

\section{Inclusion Criteria \\ SGA Group}

Babies born between 30 and 34 weeks admitted in NICU with birth weight $<10^{\text {th }}$ percentile for the gestational age

\section{AGA Group}

Babies born between 30 and 34 weeks admitted in NICU with birth weight $\geq 10^{\text {th }}$ and $<90^{\text {th }}$ percentile for gestational age

\section{Exclusion Criteria}

Out born babies, babies born to mothers with no record of expected date of confinement and babies having HIE (Hypoxic Ischemic Encephalopathy), major congenital anomalies and genetic abnormalities.

Study subjects will be recruited over a 6-month period. Gestational age is calculated from the expected date of confinement and New Ballard Score. Babies will be grouped into AGA and SGA. Anthropometry will be calculated at birth. Length is measured using infantometer with an accuracy of 0.1 $\mathrm{cm}$. Head circumference measurement using non-stretchable tape. Infants were observed for the following neonatal complications.

1. Respiratory Distress Syndrome (RDS) - Clinical features include tachypnoea, retractions, flaring of the nasal alae, grunting, and cyanosis. The classic radiographic appearance is of low-volume lungs with a diffuse reticulogranular pattern and air bronchograms.

2. Hypoglycaemia - For infant with abnormal signs or symptoms $-<45 \mathrm{mg} / \mathrm{dL}$.

3. Neonatal Hyperbilirubinaemia - Total bilirubin $\geq 12 \mathrm{mg}$ / dL.

4. Sepsis - Infection was diagnosed either by a positive blood culture or an abnormal white blood cell count and differential, positive CRP in the presence of obvious clinical signs of infection.

5. Disseminated Intravascular Coagulation (DIC) Detection will be based on clinical and laboratory findings.

6. Thrombocytopenia - Platelet count below 100,000.

7. Hypocalcaemia - Total serum calcium concentration of $<$ $7 \mathrm{mg} / \mathrm{dL}$ or an ionized calcium concentration of $<4 \mathrm{mg}$ / dL (1 mmol / L).

8. Polycythaemia - Venous haematocrit of at least $65 \%$.

9. Necrotizing Enterocolitis - Diagnosis is based on clinical characteristics, radiological and laboratory findings.

10. Patent Ductus Arteriosus - Clinical identification of murmur with confirmation by echocardiography.

11. Intraventricular Haemorrhage - Cranial ultrasonography, performed by ultrasonologist.

12. Apnoea - Pathological apnoea is when absent airflow is prolonged (usually 20 seconds or more) or accompanied by bradycardia (heart rate $<100$ beats / minute) or hypoxaemia that is detected clinically (cyanosis) or by oxygen saturation monitoring.

13. Retinopathy of Prematurity (ROP) - By indirect ophthalmoscopy by experienced ophthalmologist.

14. Developmental Assessment - Performed at 1 year of post-natal age using Bayley scales of infant and toddler development III. Test results will be summarized as scores.

\section{Statistical Analysis}

Data were entered in to excel worksheet and analysed using SPSS statistical program. There were 133 AGA babies and 80 SGA babies. They were compared for neonatal complications. 23 babies expired during the NICU stay. Follow-up study was conducted at 1 year of age. 6 babies expired before 1 year and 37 were lost to follow up.

Statistical analysis was done using the software Statistical Package for Social Studies (SPSS) version 16.0. Data was described as mean and standard deviation for normally distributed quantitative variables and as counts and percentages for qualitative variables. Chi square test and Fischer's exact test was done to find the association between categorical variables. $\mathrm{P}$ value $<0.05$ was taken as significant.

\section{RESULTS}

Of 213 preterm babies, 133 belonged to AGA and 80 belonged to SGA group. The study population had 113 male babies and 100 female babies. Male babies were more in both the groups (SGA - $52.5 \%$, AGA - $53.4 \%$ ).

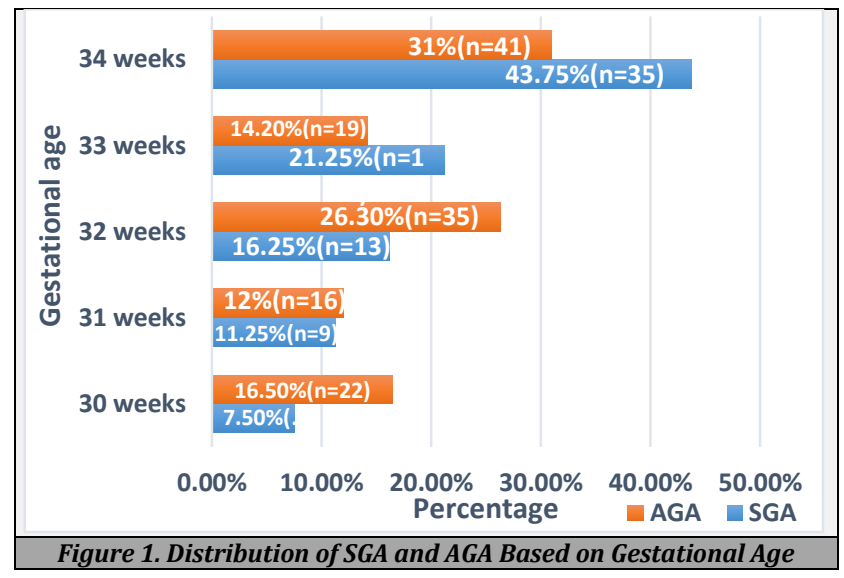

Ponderal Index was calculated and found that $71(88.8 \%)$ SGA babies had a PI of $<2$ and $9(11.2 \%)$ SGA with PI $\geq 2$. Hence, it is analysed that $88.8 \%$ of SGA babies were having asymmetrical IUGR and rest of them with symmetrical IUGR.

While $55 \%$ of SGA babies developed hypoglycaemia, only $20.3 \%$ of AGA babies developed hypoglycaemia. The difference is statistically significant. But symptomatic hypoglycaemia occurred in $9 \%$ of AGA babies while it is only $5 \%$ in SGA babies.

2 SGA and 8 AGA babies had PDA. However, comparison between the groups does not assume statistical significance ( $p$ $=0.326$ ). 4 babies required medical closure. None of them needed surgical intervention. 
$10 \%$ of SGA and $11.3 \%$ of AGA babies constituted total of 23 babies expired during the neonatal period. The difference is not statistically significant ( $\mathrm{p}=0.824$ ).

Of the 213 babies follow up study was done in 148 infants. 23 babies expired during the neonatal period. 36 infants lost to follow up and 6 infants expired after their discharge from NICU. Study population who came for follow up include 92 AGA infants and 56 SGA infants.

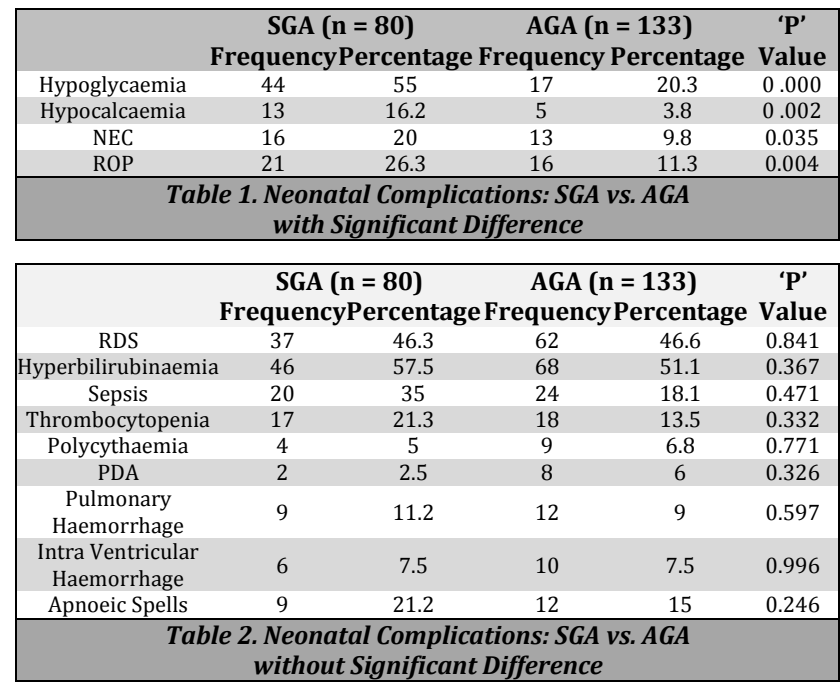

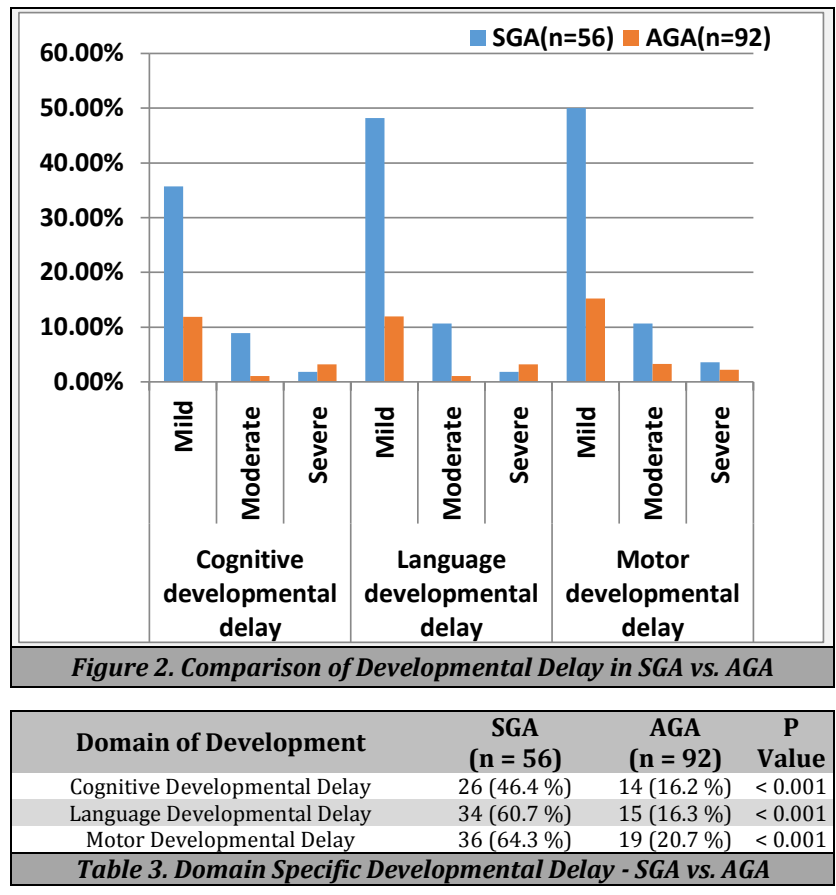

\section{DISCUSSION}

We found that the differences in cognitive, language, and motor development, between preterm SGA and AGA preterm infants at the age of 1 year were marked, indicating that there is significant additional risk of neurodevelopmental delay for children born preterm and small for gestational age. Remarkably, we found a higher number of intraventricular haemorrhage and significantly higher occurrence of hypoglycaemia in SGA than in AGA preterm infants, which could possibly explain the outcome. However, the number of babies with intraventricular haemorrhage is low which limits the possibility of association.

Studies done by Fernandez-Carrocera et al and Figueras et al found that children with IUGR had higher rates of neuromotor and neurologic abnormalities than controls at 1 year. ${ }^{32,33}$ Fernandez-Carrocera et al also found that children with IUGR scored significantly lower than controls on the Bayley Scales of Infant Development, version II (Bayley-II). ${ }^{32}$ Another study conducted by Padilla et al also concluded that, there is no significant difference in neurodevelopmental assessment at 1 year between preterm SGA and AGA ${ }^{34}$. This may be due to the fact that Padilla et al didn't employ Bayley scales, instead they applied the Hammersmith Infant Neurologic Examination. Of the 5 studies which assessed neurodevelopment of preterm SGA from 1 - 2 years, 4 indicate that these children are at increased risk for delay. ${ }^{30,34-38}$

The Bayley scales represent a well-established tool to assess the mental development in toddlers and preschool infants. ${ }^{39}$ Standardized developmental testing of SGA children at later ages could reveal in more detail difficulties in attention, language tasks and social skills as recently suggested by Strauss RS and others. ${ }^{40}$ Most studies on differences in developmental outcome between SGA and AGA; children involved with SGA showed developmental changes at the age of 5 years and older. ${ }^{41}$

In our study proportion of preterm SGA infants developing hypoglycaemia, hypocalcaemia and NEC is significantly higher compared to that of AGA group. It is believed that redistribution of blood flow in intra uterine growth restriction leads to a brain sparing effect at the expense of other organs and tissues, such as kidneys, muscles, or intestines. ${ }^{42}$ Studies by Ree IM et al showed similar results. ${ }^{43}$ This may explain the significantly higher occurrence of NEC in the SGA group. The concept of accelerated lung maturation in response to stress has been supported by some studies. ${ }^{3}$ However, in this study, we did not find any difference in the incidence of RDS between the SGA and AGA groups. However, the need for surfactant therapy in RDS is more for preterm AGA infants than SGA infants, but fails to assume statistical significance. Consistent with our results, several previous studies found no differences in the incidence of RDS between the two groups ${ }^{12}$ and studies by Thompson PJ et al even showed an increased incidence and severity of RDS in premature SGA infants. ${ }^{14}$ The concept of intrauterine growth retardation on accelerating lung maturation and improving outcome was not supported by Tyson et $\mathrm{al}^{13}$ in their study comparing SGA and AGA with the same gestational age, sex, and race.

Development of thrombocytopenia, neonatal hyperbilirubinaemia, sepsis, DIC, apnoea and pulmonary haemorrhage is observed more with SGA infants than AGA infants but lacks statistical significance. $6 \%$ of AGA infants had PDA while for SGA it was $2.5 \%$. No significant difference was noticed in the occurrence of polycythaemia and IVH among the groups. Concerning the neonatal complications of the SGA infants, controversial findings exist about the fact whether intraventricular haemorrhage occurs more often in SGA preterm infants. ${ }^{12}$ Ortigosa Rocha $\mathrm{C}$ et al found that IUGR with a gestational age of more than 33 weeks was shown to be associated with an increased risk for intraventricular haemorrhages. ${ }^{44}$ Our results show no evidence that SGA is associated with increased risks of IVH. Similarly, most previous studies found no differences in the incidence of IVH between SGA and AGA preterm neonates. ${ }^{10,11}$ However, 
because several other studies contradict these findings further research is needed to explore this issue.

It is noteworthy to note that the occurrence of ROP was found to be significantly higher in SGA. Similar observation was made by Garite et al. ${ }^{10}$

The present study didn't find any significant difference in mortality among the groups. Previous studies have shown that the mortality of infants with a birth weight below the $10^{\text {th }}$ percentile was higher than that of AGA neonates at all gestational ages up to 36 weeks. ${ }^{4}$ In the study conducted by Tyson JE et al, it was suggested that there is high mortality in SGA infants with low birth weights. ${ }^{15}$ The lack of difference in our study can be due to low proportion of SGA babies in the study. Bardin et al did not observe any significant difference in mortality between the SGA and AGA groups. ${ }^{12}$ Lackman et al also showed in a larger population-based study, that the risk of perinatal death attributed to being born preterm SGA increased significantly only with a birth weight below the third percentile, but no differences were observed in the SGA infants whose birth weights were between the 3rd and the 10th percentiles. 45

\section{What This Study Adds}

Cognitive, language and motor developmental delay is significantly more in preterm SGA compared to AGA at 1 year of age.

\section{Limitations of the Study}

Sample size is not comparable between the two groups. Follow up was limited to 1 year. Statistical significance cannot be established in subcategories owing to inadequate number in each.

\section{CONCLUSIONS}

Being born small for gestational age is significantly associated with neurodevelopmental delay for preterm babies at the age of 1 year. There is no statistically significant difference in mortality between preterm SGA and preterm AGA in $30-34$ weeks' gestation. NEC and metabolic complications like hypoglycaemia and hypocalcaemia are significantly increased in preterm SGA babies when compared to preterm AGA babies. Occurrence of ROP is also significantly high in SGA babies. Several other neonatal complications except for RDS are also more common among preterm SGA infants although they lack statistical significance.

Data sharing statement provided by the authors is available with the full text of this article at jemds.com.

Financial or other competing interests: None.

Disclosure forms provided by the authors are available with the full text of this article at jemds.com.

\section{REFERENCES}

[1] de Onis M, Blössner M, Villar J. Levels and patterns of intrauterine growth retardation in developing countries. Eur J Clin Nutr 1998;52 Suppl 1:S5-15.
[2] Sharma P, McKay K, Rosenkrantz T, et al. Comparisons of mortality and pre-discharge respiratory outcomes in small-for-gestational-age and appropriate- forgestational-age premature infants. BMC Pediatr 2004;4:9.

[3] Gluck L, Kulovich MV. Lecithin-sphingomyelin ratios in amniotic fluid in normal and abnormal pregnancy. Am J Obstet Gynecol 1973;115(4):539-46.

[4] Procianoy RS, Garcia-Prats JA, Adams JM, et al. Hyaline membrane disease and intraventricular haemorrhage in small for gestational age infants. Arch Dis Child 1980;55(7):502-5.

[5] Yamaguchi K, Hara H, Nishida H, et al. Clinical study on intrauterine growth retardation. Part 1. Outcome for small-for-gestational-age infants with very low birth weight (less than 1,500 g). Acta Paediatr Jpn 1987;29(5):742-8.

[6] Robertson CM, Etches PC, Kyle JM. Eight-year school performance and growth of preterm, small for gestational age infants: a comparative study with subjects matched for birth weight or for gestational age. J Pediatr 1990;116(1):19-26.

[7] Sung IK, Vohr B, Oh W. Growth and neurodevelopmental outcome of very low birth weight infants with intrauterine growth retardation: comparison with control subjects matched by birth weight and gestational age. J Pediatr 1993;123(4):618-24.

[8] Pena IC, Teberg AJ, Finello KM. The premature small-forgestational age infant during the first year of life: comparison by birth weight and gestational age. J Pediatr 1988;113(6):1066-73.

[9] van Hell IRD, de Leeuw R. Clinical outcome of small-forgestational age preterm infants. J Perinat Med 1989;17(2):77-83.

[10] Garite TJ, Clark R, Thorp JA. Intrauterine growth restriction increases morbidity and mortality among premature neonates. Am J Obstet Gynecol 2004;191(2):481-7.

[11] Warshaw JB. Intrauterine growth retardation: adaptation or pathology? Pediatrics 1985;76(6):998-9.

[12] Bardin C, Zelkowitz P, Papageorgiou A. Outcome of smallfor-gestational age and appropriate-for-gestational age infants born before 27 weeks of gestation. Pediatrics 1997;100(2):E4.

[13] Tyson JE, Kennedy K, Broyles S, et al. The small for gestational age infant: accelerated or delayed pulmonary maturation? Increased or decreased survival? Pediatrics 1995;95(4):534-8.

[14] Thompson PJ, Greenough A, Gamsu HR, et al. Ventilatory requirements for respiratory distress syndrome in smallfor-gestational-age infants. Eur J Pediatr 1992;151(7):528-31.

[15] Moore T, Hennessy EM, Myles J, et al. Neurological and developmental outcome in extremely preterm children born in England in 1995 and 2006: the EPICure studies. BMJ 2012;345:e7961.

[16] Tolsa CB, Zimine S, Warfield SK, et al. Early alteration of structural and functional brain development in premature infants born with intrauterine growth restriction. Pediatr Res 2004;56(1):132-8.

[17] Lodygensky GA, Seghier ML, Warfield SK, et al. Intrauterine growth restriction affects the preterm infant's hippocampus. Pediatr Res 2008;63(4):438-43.

[18] Antonow-Schlorke I, Schwab M, Cox LA, et al. 
Vulnerability of the fetal primate brain to moderate reduction in maternal global nutrient availability. Proc Natl Acad Sci USA 2011;108(7):3011-6.

[19] Krageloh-Mann I, Lidzba K. Preterm cognitive outcome and socioeconomic status. Acta Paediatr 2012;101(6):557-8.

[20] Sommerfelt K, Andersson HW, Sonnander K, et al. Cognitive development of term small for gestational age children at five years of age. Arch Dis Child 2000;83(1):25-30.

[21] Geva R, Eshel R, Leitner Y, et al. Neuropsychological outcome of children with intrauterine growth restriction: a 9-year prospective study. Pediatrics 2006;118(1):91100.

[22] O'Keeffe MJ, O'Callaghan M, Williams GM, et al. Learning, cognitive, and attentional problems in adolescents born small for gestational age. Pediatrics 2003;112(2):301-7.

[23] Klaric AS, Kolundzic Z, Galic S, et al. Language development in preschool children born after asymmetrical intrauterine growth retardation. Eur J Paediatr Neurol 2012;16(2):132-7.

[24] McCarton CM, Wallace IF, Divon M, et al. Cognitive and neurologic development of the premature, small for gestational age infant through age 6: comparison by birth weight and gestational age. Pediatrics 1996;98(6 Pt 1):1167-78.

[25] Feldman R, Eidelman AI. Neonatal state organization, neuromaturation, mother- infant interaction, and cognitive development in small-for-gestational-age premature infants. Pediatrics 2006;118(3):e869-78.

[26] Franz AR, Pohlandt F, Bode H, et al. Intrauterine, early neonatal, and postdischarge growth and neurodevelopmental outcome at 5.4 years in extremely preterm infants after intensive neonatal nutritional support. Pediatrics 2009;123(1):e101-9.

[27] Guellec I, Lapillonne A, Renolleau S, et al. Neurologic outcomes at school age in very preterm infants born with severe or mild growth restriction. Pediatrics 2011;127(4):e883-91.

[28] Morsing E, Asard M, Ley D, et al. Cognitive function after intrauterine growth restriction and very preterm birth. Pediatrics 2011;127(4):e874-82.

[29] Kan E, Roberts G, Anderson PJ, et al. The association of growth impairment with neurodevelopmental outcome at eight years of age in very preterm children. Early Hum Dev 2008;84(6):409-16.

[30] Streimish IG, Ehrenkranz RA, Allred EN, et al. Birth weight- and fetal weight-growth restriction: impact on neurodevelopment. Early Hum Dev 2012;88(9):765-71.

[31] Larroque B, Ancel PY, Marret S, et al. Neurodevelopmental disabilities and special care of 5-year-old children born before 33 weeks of gestation (the EPIPAGE study): a longitudinal cohort study. Lancet 2008;371(9615):81320.

[32] Fernandez-Carrocera LA, Chavez-Torres R, Casanueva E, et al. Intrauterine growth retardation and neurodevelopment at one year of age in Mexican children. Nutr Res 2003;23:1-8.

[33] Figueras F, Cruz-Martinez R, Sanz-Cortes M, et al. Neurobehavioral outcomes in preterm, growth-restricted infants with and without prenatal advanced signs of brain-sparing. Ultrasound Obstet Gynecol 2011;38(3):288-94.

[34] Padilla N, Perapoch J, Carrascosa A, et al. Twelve-month neurodevelopmental outcome in preterm infants with and without intrauterine growth restriction. Acta Paediatr 2010;99(10):1498-503.

[35] Batalle D, Eixarch E, Figueras F, et al. Altered small-world topology of structural brain networks in infants with intrauterine growth restriction and its association with later neurodevelopmental outcome. Neuroimage 2012;60(2):1352-66.

[36] Esteban FJ, Padilla N, Sanz-Cortés M, et al. Fractaldimension analysis detects cerebral changes in preterm infants with and without intrauterine growth restriction. Neuroimage 2010;53(4):1225-32.

[37] Padilla N, Falcón C, Sanz-Cortés M, et al. Differential effects of intrauterine growth restriction on brain structure and development in preterm infants: a magnetic resonance imaging study. Brain Res 2011;1382:98-108.

[38] Torrance HL, Bloemen MC, Mulder EJH, et al. Predictors of outcome at 2 years of age after early intrauterine growth restriction. Ultrasound Obstet Gynecol 2010;36(2):171-7.

[39] Greene MM, Patra K, Nelson MN, et al. Evaluating preterm infants with the Bayley-III: patterns and correlates of development. Res Dev Disabil 2012;33(6):1948-56.

[40] Motheral B, Brooks J, Clark MA, et al. A checklist for retrospective database studies--report of the ISPOR Task force on retrospective databases. Value Health 2003;6(2):90-7.

[41] Karlberg J, Jalil F, Lam B, et al. Linear growth retardation in relation to the three phases of growth. Eur J Clin Nutr 1994;48 Suppl 1:S25-43.

[42] Gould JB, Gluck L, Kulovich MV. The relationship between accelerated pulmonary maturity and accelerated neurological maturity in certain chronically stressed pregnancies. Am J Obstet Gynecol 1977;127(2):181-6.

[43] Ree IMC, Smits-Wintjens VEHJ, Rijntjes-Jacobs EGJ, et al. Necrotizing enterocolitis in small-for-gestational-age neonates: a matched case-control study. Neonatology 2014;105(1):74-8.

[44] Rocha CO, Bittar RE, Zugaib M. Neonatal outcomes of latepreterm birth associated or not with intrauterine growth restriction. Obstet Gynecol Int 2010;2010:231842.

[45] Lackman F, Capewell V, Richardson B, et al. The risks of spontaneous preterm delivery and perinatal mortality in relation to size at birth according to fetal versus neonatal growth standards. Am J Obstet Gynecol 2001;184(5):94653. 